\title{
PARADIGMA INTERPRETACIONISTA: A BUSCA DA SUPERACCAO DO OBJETIVISMO FUNCIONALISTA NOS ANOS 1980 E 1990
}

\author{
Sylvia Constant Vergara \\ Professora da FGV-EBAPE \\ E-mail: vergara@fgv.br
}

\author{
Miguel P. Caldas \\ Professor Associado da Loyola University New Orleans \\ E-mail: mpcaldas@oyno.edu
}

\section{INTRODUÇÃO}

Mencionou-se na introdução ao primeiro número desta série (Caldas, 2005) que os mapeamentos abrangentes do campo de estudos organizacionais revelam consistentemente que, dentre os quatro paradigmas sociológicos do modelo de Burrell e Morgan (1979), o funcionalismo - marcado pelo objetivismo e por uma sociologia focada na regulação - tem constituído por muitas décadas a "ortodoxia" na pesquisa científica da área.

Também já se apontou nesta série que o funcionalismo continua a expandir sua hegemonia até hoje no campo de estudos organizacionais, em boa parte devido à representatividade institucional do mainstream norte-americano, inclusive no Brasil, como mostram diversas revisões, mapeamentos e análises bibliométricas a esse respeito (e.g. Bertero et al., 2005; Vergara e Carvalho, 1995; M achado-da-Silva et al., 1990). 0 que tais retratos da produção acadêmica brasileira deixam evidente é, por um lado, um histórico apego ao funcionalismo como fonte praticamente hegemônica de alicerce epistemológico e, por outro, focos de resistência a essa tendência que se dividem fundamentalmente em duas vertentes contrárias à predominância funcionalista: o interpretacionismo, que cresce desde o final da década de 1970 , e os referencias críticos e pós-modernos, que se expandem principalmente após o final da década de 1980.

Com a predominância do funcionalismo como fundação epistemológica da nossa pesquisa e da educação de docentes, produziu-se no Brasil uma geração de pesquisadores e educadores em estudos organizacionais que tiveram acesso restrito a outros paradigmas de análise organizacional, assim como menos incentivo e receptividade para aprofundar-se em descobri-los, caso a eles tivessem algum acesso. 0 resultado último desse alijamento pode ser visto na nossa produção científica corrente e no ensino de teoria organizacional empreendido atualmente no Brasil, com uma nítida limitação ao funcionalismo básico, tipicamente contigencialista sistêmico. Mais uma vez, honrosas exceções eram encontradas em al guns dos principais programas de pósgraduação filiados à Anpad, possivelmente pela maior facilidade de acesso a publicações estrangeiras ou a grupos de pesquisa al ternativos que contataram no exterior. Graças a tais exceções, ainda se pôde ver, no Brasil dos anos 1980 e 1990, um fluxo razoável de "pesquisa alternativa" ao funcionalismo, que, mais uma vez, tendia a dividir-se entre interpretacionistas, por um lado, e críticos ou pós-modernos, por outro.

0 que marca a diferença entre o funcionalismo e essas duas vertentes principais que a ele se opuseram nas últimas décadas é nítido, e, mais uma vez, pode-se entendê-la pelo marco de Burrell e M organ (1979), como discutido no primeiro número desta série e que é o seguinte: fundamentalmente, o interpretacionismo questiona o objetivismo arraigado na doutrina funcionalista, enquanto a vertente crítica combate sua inclinação à regulação e à manutenção da ordem social, ou seja, a sua falta de engajamento em prol da mudança social.

Como prometido no primeiro número desta série, iremos neste e no próximo número da RAE, na seção "RAE-clássicos", dar maior divulgação e acesso justamente a essas duas vertentes, que, no contra-fluxo do funcionalismo, deram al ternativas ao campo nos últi- 
mos anos. Neste quarto número da série, nosso interesse é apresentar dois textos que auxiliem a introduzir o intepretacionismo a pesquisadores que até hoje não tiveram maior acesso a eles, e também procurar mostrar as principais direções que os estudos de orientação interpretacionista tomaram nos últimos 20 ou 25 anos. No quinto e último número previsto para a série, será apresentada a vertente que inclui os estudos críticos e pós-modernos.

\section{A COMPREENSÃO DO INTER PRETACIONISMO EM ANÁLISE ORGANIZACIONAL}

Como mencionado na introdução, a essência da crítica interpretacionista foca-se no objetivismo exacerbado, e até certo ponto limitante, do funcional ismo. Para os funcionalistas, as organizações são objetos tangíveis, concretos e objetivos. Para os interpretacionistas, as organizações são processos que surgem das ações intencionais das pessoas, individual mente ou em harmonia com outras. Elas interagem entre si na tentativa de interpretar e dar sentido ao seu mundo. A realidade social é, então, uma rede de representações complexas e subjetivas.

Os dois artigos apresentados neste número da RAE podem ser vistos como um dos possíveis acessos a caminhos essenciais do interpretacionismo. Buscar visualizar essa corrente de pensamento em contexto mais amplo é o que fazemos a seguir. Para tanto, recorremos aos posicionamentos filosóficos de realistas e de idealistas, resgatamos o mapeamento sociológico elaborado por Burrell e Morgan e apresentamos três importantes enfoques interpretacionistas: o solipsismo, a fenomenologia e a hermenêutica. Em seguida, da fenomenologia destacamos duas escolas de pensamento: a etnometodologia e o interacionismo simbólico. Após esse destaque, reportamonos a algumas das pesquisas realizadas no Brasil. Concluímos apontando tendências futuras.

\section{REALISMO E IDEALISMO}

Para nos dar lições preliminares de filosofia, Morente (1980) conduz toda a sua argumentação orientada pela seguinte questão: o que é o que existe? Apresenta diferentes respostas de diferentes filósofos, inclusive as dos racionalistas e as dos idealistas. Para os primeiros, iluminados por Aristóteles, a resposta é dada pelo conhecimento advindo da lógica, da matemática e da física. Põem ênfase na razão, na problemática do método e na critica. As coisas formadas pelo mundo formam o conjunto das coisas reais. Para os idealistas, a resposta é outra. 0 que existe é 0 absoluto, 0 incondicionado, o espiritual, que se manifesta fenomenologicamente. A Kant (1724-1803) muito se deve da el aboração desse pensamento, pois é de sua ontologia e epistemologia que os filósofos pós-kantianos partem, embora em muitos aspectos possam dele se afastar e até negá-lo (Burrell e Morgan, 1979; M arcondes, 1997). Tais filósofos conformam o idealismo alemão póskantiano, cujos expoentes são Johann Fichte (17621814) e Friederich Schelling (1775-1854). Ao idealismo eles se referem como transcendental, subjetivo e absoluto. Fichte busca superar a dicotomia sujeitoobjeto, unificando o mundo do sensível e o do inteligível e justificando a existência de um objeto sobre 0 qual recai a ação, essência do eu. Diferentemente de Fichte, Schelling assevera que a essência do eu é a harmonia, a identidade, a síntese dos contrários. Esses filósofos abandonam a crítica e a fundamentação do conhecimento, características do racionalismo moderno, e buscam superar os limites daí advindos, pela intuição e pela experiência estética (A bbagnano, 1970; Marcondes, 1997; Morente, 1980).

Os racionalistas e os ideal istas têm servido de suporte ao estudo das organizações. Os primeiros, iluminando o funcionalismo, tão caro à prática da Administração, bem como pesquisas cuja metodologia é amparada pelos pressupostos positivistas. Os idealistas, por seu turno, têm iluminado reações ao funcionalismo/positivismo. Veja-se, por exemplo, os trabaIhos de David Silverman, de Karl Weick e os da linha marxista. Silverman, em The Theory of Organization (1971), apresenta uma teoria com enfoque subjetivista, orientada para uma interpretação da ação humana. Weick, cuja influência em estudos organizacionais tem sido expressiva, argumenta em sua clássica obra The Social Psychology of Organizing (1969) que as organizações são processos de natureza dinâmica e fluida. Tais processos, produzidos pela interação humana, mudam cooperativa e conflitantemente. O rganizações são verbos, não substantivos.

0 primeiro artigo traduzido neste número da série - 0 artigo de Daft e Weick - deve ser visto como uma amostra a esse tipo de orientação interpretacionista, subjetiva e fluida, da interação humana em organizações.

É ao positivismo sociológico e ao idealismo alemão que se referem Burrell e M organ (1979) quando fazem um mapeamento de diferentes abordagens teórico- 
metodológicas e formulam sua clássica obra sobre paradigmas sociológicos e análise organizacional.

\section{MAPEAMENTO DE BURRELL E MORGAN}

Enfatizando que todas as teorias de organização são baseadas em uma filosofia da ciência, ou seja, em suposições relacionadas à ontologia, à epistemologia, à natureza humana e à metodologia, Burrell e Morgan vêem o positivismo e o ideal ismo alemão como as pontas de um continuum cujas características são, respectivamente, uma abordagem objetivista às ciências sociais e uma subjetivista. A primeira vê o mundo em uma perspectiva realista, tem uma visão determinística da natureza humana e usa o método nomotético, isto é, o que oferece leis. A segunda parte da premissa de que a realidade última do universo repousa no espírito, na idéia, mais do que na percepção sensorial .

Pesquisas empíricas de cunho objetivista buscam identificar relações entre variáveis, estabelecem hipóteses, testam-nas, utilizam critérios probabilísticos para a definição de amostras, usam instrumentos estruturados para a col eta de dados e técnicas estatísticas para o seu tratamento. Buscam a generalização. Pesquisas empíricas de cunho subjetivista contemplam a visão de mundo dos sujeitos, definem amostras intencionais, selecionadas por tipicidade ou por acessibilidade, obtêm os dados por meio de técnicas pouco estruturadas e os tratam por meio de análise de cunho interpretativo. Os resultados obtidos não são general izáveis.

Como foi visto no primeiro número desta série ( $C$ aldas, 2005), Burrell e Morgan (1979) definem quatro paradigmas sociológicos com base no subjetivismo e no objetivismo. Acrescentam a esses critérios dois outros: ordem e mudança. A partir daí definem como sendo uma abordagem objetivista à análise dos fenômenos sociais dois paradigmas: o funcionalista, associado à ordem, e o estruturalista radical, associado à mudança. Definem como uma abordagem subjetivista igual mente dois paradigmas: o interpretacionista, relativo à ordem, e o humanista radical, relativo à mudança. Vejamos a seguir, com mais detalhes, o chamado paradigma interpretacionista.

\section{PARADIGMA INTERPRETACIONISTA}

Na visão de Burrell e Morgan (1979), o paradigma interpretacionista abraça um amplo espectro de pen- samentos filosóficos e sociológicos que compartilham a característica comum de tentar compreender e explicar o mundo social a partir do ponto de vista das pessoas envolvidas nos processos sociais. Incluem nele o solipsismo, a fenomenologia e a hermenêutica. Embora com características distintivas, esses pensamentos têm em comum a preocupação em compreender a experiência subjetiva dos indivíduos. Suas teorias são construídas não do ponto de vista do observador da ação; antes, daquel e que age. A realidade social, para eles, é um processo emergente, uma extensão da consciência humana e da experiência subjetiva.

No mapeamento de Burrell e Morgan, o solipsismo é a forma mais extrema do idealismo/subj etivismo, tanto do ponto de vista da ordem quanto do ponto de vista da mudança. Por esse motivo, incluem o solipsismo no paradigma interpretacionista e também no humanista radical. Para o solipsista, o mundo é a criação de sua mente. Ontologicamente, não há existência de coisa alguma, além do que a pessoa percebe em sua mente e em seu corpo. Se for assim, como o personagem Hamlet, de Shakespeare, a pessoa só ouve a si mesma.

A fenomenologia, a partir do trabalho de Edmund Husserl (1859-1938), toma várias direções. Assim, Scheller, Heidegger, Schutz, Sartre, M erleau-Ponty trazem contribuições distintas. Podem-se identificar dois tipos de fenomenologia: a transcendental e a existencial. 0 primeiro tipo tem sido abraçado por teóricos que adotam uma perspectiva pertencente ao paradigma hu manista radical. Vêem transcendência como um potencial para a libertação do cotidiano. 0 segundo tipo pode ser percebido nos trabalhos de Heiddeger, Sartre, Merleau-Ponty e Schutz. Então surge a fenomenologia descritiva, a realista, a constitutiva, a existencial e a hermenêutica.

Segundo a fenomenologia hermenêutica, preconizada por Martin Heidegger (1889-1976), a existência humana é interpretativa. Do ponto de vista hermenêutico, há de se buscar a essência do objeto, ou seja, os atributos sem os quais ele não pode ser identificado. A hermenêutica, como as outras variações da fenomenologia, preocupa-se em compreender e interpretar os produtos da mente humana, que constroem 0 mundo social e cultural (Burrell e Morgan, 1979; Moreira, 2004; Ray, 1994; Sanders, 1982). É no escopo da fenomenologia que se inserem duas escolas de pensamento cujos pressupostos são bastante utilizados no estudo das organizações: a etnometodologia e o interacionismo simbólico. 


\section{ETNOMETODOLOGIA E INTERACIONISMO SIMBÓLICO}

A etnometodologia, com suas raízes na fenomenol ogia, caracteriza-se pelo estudo detalhado do cotidiano da vida. Origina-se, particularmente, da fenomenologia de Alfred Schutz. 0 termo foi cunhado por Harold Garfinkel, na década de 1940, na Universidade de Chicago. A etnometodologia busca descobrir como e o que as pessoas fazem na sua vida diária em sociedade para construir a realidade social, bem como a natureza da realidade construída. Assume que a prática da vida cotidiana é interpretada pel as pessoas individual mente ou em interação com outras. 0 conhecimento que as pessoas adquirem é o do dia-a-dia, definindo o que é a realidade para elas. Como se baseia no fato relatado, a fala das pessoas assume relevância na etnometodologia. A modificação do ambiente e a busca de teorização não é preocupação desse estudo (Haguette, 1987).

0 interacionismo simbólico tem suas origens no trabalho de George Herbert M ead (1863-1947), porém esse termo (interacionismo simbólico) foi cunhado por Herbert Blumer, seguidor de M ead (Blumer, 1986). Ao de Blumer se contrapõe o trabal ho de M anford Kuhn. 0 primeiro personifica a Escola de C hicago e o segundo, a de lowa (Fine, 1993; Haguette, 1987). Embora os dois pensadores discordem em termos de campo metodológico e níveis de interação simbólica, el es têm em comum a crença segundo a qual a pessoa age em relação a al go - pessoas ou coisas - , com base nos significados que esse algo tem para ela. Tal significado não só se origina de algum tipo de interação social, como também é estabelecido e modificado pela interpretação das pessoas sobre outras pessoas e coisas (Blumer, 1986; Bryman, 1995). As situações de interação são construções fenomenológicas (Denzin, 1983). 0 interacionismo simbólico sublinha o aspecto subjetivo do comportamento humano presente no grupo social e tem como princípio fundamental que pessoas, individual ou grupalmente, existem em ação. É o organizing, de que nos fala Weick.

Burrell e Morgan (1979, p. 271) apresentam a sutil diferença entre a etnometodologia e o interacionismo simbólico. Ela diz respeito ao grau de atenção dado à maneira segundo a qual a realidade é negociada por meio da interação. A etnometodologia geral mente focaliza o modo como os indivíduos se responsabilizam por seu mundo e lhe dão um sentido. 0 interacionismo simbólico focaliza o contexto social no qual os indivíduos, ao interagir, empregam uma variedade de práti- cas para criar e manter definições particulares do mundo; realidades e fatos são criações sociais.

No escopo do interpretacionismo, o interacionismo simbólico tem sido considerado de grande importância. Incluem-se nessa corrente de pensamento os estudos organizacionais que buscam desvendar as ações, os sentidos que orientam as ações, a interação social da qual emergem os sentidos e as formas como as pessoas interpretam as coisas e, com base nessa interpretação, modificam os sentidos.

Em termos metodológicos, o interacionismo simbólico se vale da observação simples ou participante, de entrevistas individuais ou grupais, de histórias de vida, de cartas, diários, de painéis de discussão, de conversas, de documentos públicos. 0 estudo de caso também Ihe é pertinente (Godoy, 1995; M aines, 1977; Mendonça, 2001; Stryker, 1987).

\section{PESQUISA ORGANIZACIONAL INTERPRETACIONISTA NO BRASIL}

Os pressupostos do interpretacionismo estão presentes em trabalhos de diversos pesquisadores de estudos organizacionais em nosso país. Alguns abordam o pensamento e o método fenomenológico de forma bem acessível aos iniciantes, como Moreira (2002, 2004). U m exemplo interessante, mas na área de marketing, é a tese de doutoramento de Carvalho (2003). Outros abordam o interacionismo simbólico, como Godoy (1995) e M endonça $(2001,2002)$.

Outros, ainda, debruçam-se sobre a etnometodologia na perspectiva antropológica. Por exemplo, as etnografias de Bresler (1993), Castilhos e Cavedon (2004), Cavedon (1999, 2001, 2003), Jaime Júnior (1996), Lengler e Cavedon (2001), Serva (2002), Vasconcelos, Mascarenhas e Protil (2004). A etnografia tem se popularizado no Brasil, e os trabalhos já publicados revelam essa expansão embrionária. M esmo em áreas como 0 marketing (e.g. Barros, 2002, 2004) e finanças (e.g. Fonseca, 1998), que têm tradição objetivista mais arraigada, parecem mostrar promissores sinais de maior abertura ao método etnográfico. A coleta de dados é feita por meio de observação simples ou participante, entrevistas, fotografias. 0 diário de campo Ihe é pertinente.

Muitos outros pesquisadores utilizam o interpretacionismo como alicerce, sem, no entanto, dedicar-se a analisá-lo e aos seus métodos e modelos per se. Em temas como cultura e simbolismo, identidade, poder, 
emoção, relações de gênero, estética, espiritualidade e muitos outros, é fácil perceber o alicerce interpretacionista. Veja-se, por exemplo, o trabal ho de Silva e Vergara (2003) sobre sentimentos e subjetividade presentes nas supostas resistências à mu dança e a coletânea organizada por Davel e Vergara (2001), que, enfocando a questão da subjetividade, apresentam temas como inovação, cognição, poder, comunicação, interioridade, prazer, emoção, gênero, relações amorosas e familiares e cultura, discutidos por Bastos, Townley, Enriquez, Prestes M otta, Burrell, Rouleau, Freitas, Tonelli, Alter, Zarifian, Alcadipani e Bresler.

Se a incipiente produção com inspiração interpretacionista no Brasil já mostra grande riqueza, parece óbvio que em termos de direção de pesquisa futura 0 intepretacionismo tem significativo potencial de contribuição à área de estudos organizacionais no país. As direções e caminhos dessa produção são inúmeros, e se revelam em diversas dimensões. É bem verdade que ainda há um grande volume de trabal hos de orientação subjetivista que, talvez pela carência de referencial al ternativo à hegemonia objetivista, inadequadamente utilizam a base funcional ista, sempre mais acessível e bem recebida no país. Também há aqueles cujos autores afirmam usar tal ou qual método sem que, no entanto, essa afirmação se confirme aos olhos do leitor atento. A exploração mais detida do referencial interpretacionista poderia dar a muitos desses autores maior conforto epistemológico, maior adequação metodológica, bem como maior profundidade e ressonância às suas conclusões.

\section{PARA CONCLUIR}

Morente, que invocamos no início deste texto, nos provoca: 0 que é o que existe? Podemos perguntar: 0

Quadro 1 - Pressupostos básicos do debate subjetivismo x objetivismo nas ciências sociais.

\begin{tabular}{|c|c|c|c|c|c|c|}
\hline & \multicolumn{2}{|c|}{ ABORDAGENS SUBJETIVISTAS } & \multicolumn{4}{|c|}{ ABORDAGENS OBJETIVISTAS } \\
\hline $\begin{array}{l}\text { Pressupostos } \\
\text { ontológicos } \\
\text { centrais }\end{array}$ & $\begin{array}{l}\text { Realidade como } \\
\text { uma projeção } \\
\text { da imaginação } \\
\text { humana }\end{array}$ & $\begin{array}{l}\text { Realidade como } \\
\text { uma construção } \\
\text { social }\end{array}$ & $\begin{array}{l}\text { Realidade como } \\
\text { um campo de } \\
\text { discurso } \\
\text { simbólico }\end{array}$ & $\begin{array}{l}\text { Realidade como } \\
\text { um campo } \\
\text { contextual de } \\
\text { informação }\end{array}$ & $\begin{array}{l}\text { Realidade } \\
\text { como um } \\
\text { processo } \\
\text { concreto }\end{array}$ & $\begin{array}{l}\text { Realidade } \\
\text { como uma } \\
\text { situação } \\
\text { concreta }\end{array}$ \\
\hline $\begin{array}{l}\text { Pressupostos } \\
\text { sobre a } \\
\text { natureza } \\
\text { humana }\end{array}$ & $\begin{array}{l}\text { Homem como } \\
\text { puro espírito, } \\
\text { consciência, } \\
\text { ser }\end{array}$ & $\begin{array}{l}\text { Homem como } \\
\text { um construtor } \\
\text { social, o criador } \\
\text { de símbolos }\end{array}$ & $\begin{array}{l}\text { Homem como } \\
\text { um ator, } 0 \\
\text { usuário de } \\
\text { símbolos }\end{array}$ & $\begin{array}{l}\text { Homem } \\
\text { como um } \\
\text { processador } \\
\text { de informações }\end{array}$ & $\begin{array}{l}\text { Homem como } \\
\text { um adaptador }\end{array}$ & $\begin{array}{l}\text { Homem como } \\
\text { um respondente }\end{array}$ \\
\hline $\begin{array}{l}\text { Estâncias } \\
\text { epistemológi- } \\
\text { cas básicas }\end{array}$ & $\begin{array}{l}\text { Para obter } \\
\text { insight } \\
\text { fenomenológico, } \\
\text { revelação }\end{array}$ & $\begin{array}{l}\text { Para entender } \\
\text { como a } \\
\text { realidade social } \\
\text { é criada }\end{array}$ & $\begin{array}{l}\text { Para entender } \\
\text { padrões do } \\
\text { discurso } \\
\text { simbólico }\end{array}$ & $\begin{array}{l}\text { Para mapear } 0 \\
\text { contexto }\end{array}$ & $\begin{array}{l}\text { Para estudar os } \\
\text { sistemas, os } \\
\text { processos, a } \\
\text { mudança }\end{array}$ & $\begin{array}{l}\text { Para construir } \\
\text { uma ciência } \\
\text { positivista }\end{array}$ \\
\hline $\begin{array}{l}\text { Algumas } \\
\text { metáforas } \\
\text { permitidas }\end{array}$ & Transcendental & $\begin{array}{l}\text { Jogo da } \\
\text { linguagem, } \\
\text { realização, texto }\end{array}$ & Teatral, cultural & Cibernética & Orgânica & Mecânica \\
\hline $\begin{array}{l}\text { Métodos de } \\
\text { pesquisa }\end{array}$ & $\begin{array}{l}\text { Exploração de } \\
\text { pura subjetivi- } \\
\text { dade }\end{array}$ & Hermenêutica & $\begin{array}{l}\text { Análise } \\
\text { simbólica }\end{array}$ & $\begin{array}{l}\text { Análise } \\
\text { contextual das } \\
\text { Gestalten }\end{array}$ & $\begin{array}{l}\text { Análise } \\
\text { histórica }\end{array}$ & $\begin{array}{l}\text { Experimentos } \\
\text { de laboratório, } \\
\text { surveys }\end{array}$ \\
\hline $\begin{array}{l}\text { Alguns } \\
\text { exemplos de } \\
\text { pesquisa }\end{array}$ & Fenomenologia & Etnometodologia & $\begin{array}{l}\text { Teoria da } \\
\text { ação social }\end{array}$ & Cibernética & $\begin{array}{l}\text { Teoria dos } \\
\text { sistemas abertos }\end{array}$ & Behaviorismo \\
\hline
\end{tabular}

Fonte: Morgan e Smircich (1980). Adaptado por Mendonça (2001). 
que é uma organização? Empaticamente nos colocando como interpretacionistas, dizemos: organizações são processos, são teias de significados, de representações, de interpretações, de interações, de visões compartiIhadas dos aspectos objetivos e subjetivos que compõem a realidade de pessoas, de movimento, de ações de pessoas individual, grupal e socialmente consideradas. $\mathrm{N}$ ão é sem alguma razão que muitos pesquisadores, motivados a estudar diversidade, paradoxo, cultura, poder, processos de comunicação, organizações culturais (altamente simbólicas) e organizações prestadoras de serviço, têm abraçado essa corrente de base subjetivista.

No entanto, o esforço agora é de superar a dicotomia objetivismo/subjetivismo. No mapeamento de Burrell e Morgan, o interpretacionismo diz respeito a uma abordagem subjetivista da ontologia, da epistemol ogia, da natureza humana e da metodologia. Esses pensadores, que tanto nos auxiliaram com seu mapeamento, contribuíram também para uma visão exclusivista de cada paradigma por el es identificado, já que os consideraram mutuamente excludentes. Tal visão sofre críticas e tem desencadeado pesquisas reativas, as quais buscam superar a dicotomia apontada.

Em trabalho posterior, M organ, dessa vez com Linda Smircich (1980), dão um primeiro passo, embora ainda tênue, para amenizar essa dicotomia. M organ e Smircich sugerem fronteiras mais permeáveis e a possibilidade de muitos matizes entre as inclinações subjetivistas e objetivistas num continuum (veja a Figura 1): entre um e outro ponto, as transições seriam mais sutis, e não se excluiria a inspiração de uma pelas outras.

Em Max Weber (1864-1920) já é possível encontrar uma contribuição importante para superar tal dicotomia, quando ele constrói a noção de tipo ideal. Argumentam Burrell e Morgan que os tipos ideais permitem a ordenação de elementos da realidade, incorporando o espírito que caracteriza fenômenos individuais em um todo generalizado muito mais amplo. No entanto, a sociologia interpretacionista de Weber é uma abordagem bastante limitada do subjetivismo, quando comparada, por exemplo, à filosofia de Edmund Husserl.

Em estudos organizacionais, seja com a aceitação de que organizações são movimentos objetivos e subjetivos, seja real izando conversações entre os paradigmas delineados por Burrell e Morgan, seja utilizando, complementarmente, métodos quantitativos e qualitativos de pesquisa na captação da realidade, têm-se feito esforços na direção da superação da dicotomia objetivismo/subjetivismo.
Interpretacionistas e funcionalistas juntam-se a outros no processo de fazer ciência. Como esta não é dogma, carrega em si reflexões, reações, contradições, dúvidas, num processo dinâmico que revela, sobretudo, o fato de que a realidade social, grupal, individual transborda de nossa capacidade de dela dar conta. Parodiando Heidegger, ousamos dizer que uma pesquisa científica vê cumprido seu objetivo quando seu final vem a ser o que era no início: uma pergunta.

\section{REFERÊNCIAS BIBLIOGRÁFICAS}

ABBAGNAN O, N. Dicionário de filosofia. São Paulo: Mestre Jou, 1970.

BARROS, C. F. Marketing e etnografia: um levantamento em journals dos anos 80 e 90. In: ENCONTRO ANUAL DA ASSOCIAÇÃO NACIONAL DOS PROGRAMAS DE PÓS-GRADUAÇÃO EM ADMINISTRAÇÃO, 26., 2002, Salvador. Anais. Salvador: AN PAD, 2002.

BARROS, C. F. Classificação de restaurantes a partir da visão do consumidor: um estudo etnográfico. In: EN CONTRO ANUAL DA ASSOCIAÇÃO NACIONAL DOS PROGRAMAS DE PÓS-GRADUAÇÃO EM ADMINISTRAÇÃO, 28., 2004, Curitiba. Anais. Curitiba: AN PAD, 2004.

BURRELL, G.; MORGAN, G. Sociological Paradigms and Organizational Analysis. London: Heinemann Educational Books, 1979.

BERTERO, C.; CALDAS, M.; W OOD, T. Produção científica em administração no Brasil: o estado-da-arte. São Paulo: Atlas, 2005.

BLUMER, H. Symbolic Interactionism: Perspective and M ethod. Berkeley: University of California Press, 1986.

BRESLER, R. R. B. Organizações e programas de integração: um estudo sobre a passagem. 1993. Dissertação (M estrado) - Escola de Administração de Empresas de São Paulo da Fundação Getúlio Vargas (FGV-EAESP), São Paulo, 1993.

BRYMAN, Alan. Quantity and Quality in Social Research. London: Routledge, 1995.

BURRELL, G.; MORGAN, G. Sociological Paradigms and Organizational Analysis. London: Heinemann Educational Books, 1979.

CALDAS, M. P. Paradigmas em estudos organizacionais: uma introdução à série. Revista de Administração de Empresas, v. 45, n. 1, p. 53-57, 2005.

CARVALHO, J. L. F. S. A luz nos cenários de serviços: fenomenologia da experiência interativa dos participantes dos encontros de serviços com a iluminação ambiental. 2003. 300 f. Tese (Doutorado em Administração) Departamento de Administração, Pontifícia Universidade Católica do Rio de Janeiro, Rio de Janeiro, 2003. 
CASTILHOS, R.; CAVEDON, N. R. Mercado público de Porto Alegre: um espaço organizacional dividido entre o sagrado e o profano. Revista Eletrônica de Administração - REAd, Porto Alegre, v. 10, n. 1, 2004.

CAVEDON, N. R. O método etnográfico em estudos sobre cultura organizacional: implicações positivas e negativas. In: ENCONTRO NACIONAL DA ASSOCIAÇÃO DOS PROGRAMAS DE PÓS-GRADUAÇÃO EM ADMINISTRAÇÃO , 23., 1999, Foz do I guaçu. Anais. Foz do I guaçu: AN PAD, 1999.

CAVEDON, N. R. Recursos metodológicos e formas alternativas no desenvolvimento e na apresentação de pesquisas em administração. In: ENCONTRO NACIONAL DA ASSOCIAÇÃO NACIONAL DOS PROGRAMAS DE PÓS-GRADUAÇÃO EM ADMINISTRAÇÃO, 25., 2001, Campinas. Anais. Campinas: AN PAD, 2001.

CAVEDON, N. R. Antropologia para administradores. Porto Alegre: UFRGS, 2003.

DAVEL, E.; VERGARA, S. C. Gestão com pessoas e subjetividade. São Paulo: Atlas, 2001.

DENZIN, N. K. Interpretative interactionism. In: MORGAN, G. (Ed.). Beyond M ethod: Strategies for Social Research. London: Sage, 1983.

FINE, G. A. The sad demise, mysterious disappearance, and glorious triumph of symbolic interactionism. Annual Review of Sociology, v. 19, p. 61-87, 1993

FON SECA, A. C. P. D. Percepções de incerteza em um sistema de planejamento e controle: um estudo etnográfico Brasil-Inglaterra. In: ENCONTRO ANUAL DA ASSO CIAÇÃO NACIONAL DOSPROGRAMASDE PÓSGRADUAÇÃO EM ADMINISTRAÇÃO, 22., 1998, Foz do Iguaçu. Anais. Foz do Iguaçu: AN PAD, 1998.

GODOY, A. S. Introdução à pesquisa qualitativa e suas possibilidades. Revista de Administração de Empresas, v. 35, n. 2, p. 57-63, 1995.

HAGUETTE, T. M. F. Metodologias qualitativas na sociologia. Petrópolis: Vozes, 1987.

JAIME JÚNIOR, P. Etnografia, antropologia e o universo organizacional. Revista de Administração Pública, v. 30, n. 6, p. 105-121, 1996.

LENGLER, J.; CAVEDON, N. R. Um olhar etnográfico desconstrutivo sobre os ritos no shopping center. In: ENCONTRO NACIONAL DA ASSOCIAÇÃO NACIONAL DOS PROGRAMAS DE PÓS-GRADUAÇÃO EM ADMINISTRAÇÃO, 25., 2001, Campinas. Anais. Campinas: AN PAD, 2001.

MACHADO-DA-SILVA, C. L.; CUNHA, V. C.; AMBONI, N. Organizações: 0 estado da arte da produção acadêmica no Brasil. In: EN CONTRO ANUAL DA ASSO CIAÇÃO NACIONAL DOSPROGRAMASDE PÓS-GRADUAÇÃO EM ADMINISTRAÇÃO, 14., 1990, Florianópolis. Anais. Florianópolis: ANPAD, 1990.

MAINES, D. R. Social organization and social structure in symbolic interactionist thought. Annual Review of Sociology, v. 3, p. 235-259, 1977.
MARCONDES, D. Iniciação à história da filosofia. Rio de Janeiro: Jorge Zahar, 1997.

MEN DON ÇA, J. R. C. Interacionismo simbólico: uma sugestão metodológica para a pesquisa em Administração. In: EN CONTRO ANUAL DA ASSOCIAÇÃO NACIONAL DOS PROGRAMAS DE PÓS-GRADUAÇÃO EM ADMINISTRAÇÃO , 25., 2001, Campinas. Anais. Campinas: AN PAD, 2001.

MOREIRA, D. A. Pesquisa em administração: origens, usos e variantes do método fenomenológico. In: EN CONTRO NACIONAL DA ASSOCIAÇÃO NACIONAL DOS PROGRAMAS DE PÓS-GRADUAÇÃO EM ADMINISTRAÇÃO, 26., 2002, Salvador. Anais. Salvador: AN PAD, 2002.

MOREIRA, D. A. 0 método fenomenológico na pesquisa. São Paulo: Pioneira Thomson, 2004.

MORENTE, M. G. Fundamentos de filosofia: lições preliminares. São Paulo: Mestre Jou, 1980.

MORGAN, G.; SMIRCICH, L. The case for qualitative research. Academy of Management Review, v. 5, n. 4, p. 491-500, 1980.

RAY, M. A. The richness of phenomenology: philosophic, theoretic, and methodologic concerns. In: MORSE, J. (ED.). Critical Issues in Qualitative Research M ethods. London: Sage, 1994.

SANDERS, P. Phenomenology: a new way of viewing organizational research. Academy of M anagement Review, v. 7, n. 3, p. 353-360, 1982.

SERVA, M. Observação participante, etnografia e pesquisa em Administração: desafios e possibilidades. In: ENCONTRO ANUAL DA ASSOCIAÇÃO NACIONAL DOSPROGRAMASDE PÓS-GRADUAÇÃO EM ADMINISTRAÇÃO, 26., 2002, Salvador. Anais. Salvador: AN PAD, 2002.

SILVA, J. R. G.; VERGARA, S. C. Sentimentos, subjetividade e supostas resistências à mudança organizacional. Revista de Administração de Empresas, v. 43, n. 3, p. 10-21, 2003.

SILVERMAN, D. The theory of organizations: a sociological framework. London: Heinemann, 1971.

STRYKER, S. The vitalization of symbolic interactionism. Social Psychology Quarterly, v. 50, n. 1, p. 83-94, 1987.

VASCONCELOS, I.; MASCARENHAS, A. O.; PROTIL, R. M. Paradoxos culturais na gestão de pessoas: cultura e contexto em uma cooperativa agroindustrial. RAE-eletrônica, v. 3, n. 1, 2004.

VERGARA, S. C.; CARVALHO JR., D. S. Nacionalidade dos autores referenciados na literatura brasileira sobre organizações. In: EN CONTRO ANUAL DA ASSOCIAÇÃO NACIONAL DOS PROGRAMAS DE PÓSGRADUAÇÃO EM ADMINISTRAÇÃO, 19., 1995, João Pessoa. Anais. João Pessoa: AN PAD, 1995.

WEICK, K. The Social Psychology of Organizing. Reading, MA: AddisonWesley, 1969. 